\title{
Ethics of social networks for special needs users
}

\author{
Caroline Rizza $\cdot$ Ângela Guimarães Pereira
}

Published online: 27 November 2013

(c) European Union 2013

This special issue complements and extends the conversations held at a workshop on cyber-bullying in the teenager populations organised by the Joint Research Centre of the European Commission ${ }^{1}$ in the fall of 2012. In this workshop several worlwide experts contributed to a discussion on the ethical, legal and governance issues related to the cyber-bullying phenomenon.

Millions of persons around the world are regular users of social networking sites. Their number is still on the rise, despite indications that there are people dropping out of the most popular sites. While their social and political functions are widely recognised, online social networking practices are also enhancing or creating new problems with regard to the rights, needs and interests of vulnerable citizens, such as children, women in many cases, the elderly, persons with disabilities, as well as citizens in precarious social or economical situations (e.g. unemployed). These categories represent what we here call "special needs users", i.e. people with often limited legal capacity, their social networking practices raising specific challenges for which care and different types of solidarity are key. Hence, many of the discussions about understanding, supporting or helping "special needs users" with the use of Social

The opinions on this paper are those of the authors and cannot be considered as official positions of the European Commission.

C. Rizza $(\bowtie)$

Telecom ParisTech, Institut Telecom, 46 Rue Barrault,

75013 Paris, France

e-mail: caroline.rizza@telecom-paristech.fr

Â. Guimarães Pereira $(\bowtie)$

European Commission, Joint Research Centre,

Via Enrico Fermi, 2749, 21027 Ispra, VA, Italy

e-mail: angela.pereira@jrc.ec.europa.eu
Networks (SN) revolve around arguments that include e-inclusion, accessibility to social networks, protection from harm and exploitation, and, in order to accommodate these users' special needs, strategies to support their social emancipation and political participation, as well as to encourage solidarity and partnerships among them and with the wider society.

This special issue invited submissions of original research exploring the interplay between Ethics, on-line social networks, and special needs users. Social sciences and Interdisciplinary studies have seen an increasing number of papers related to Facebook, Google +, LinkedIn, etc., but most of the literature reflecting on ethical questions associated with these technologies focuses on considerations about individuals' privacy. In this special edition, we wanted to explore a broader range of ethical issues raised by $\mathrm{SN}$, with a specific focus on "special needs users", for example, dignity, agency, equality, autonomy and freedom, and usability. The five papers in this special issue attempt to respond to our original question: "what are the specific ethical considerations that need to be addressed in the design, deployment and governance of social networks use by special needs persons?" They address ethical issues related to, for instance, autonomy, responsibility, agency, trust, as well as privacy, dealing with issues such as minimum age and protection of minors, youth development, cyber-bullying and cyber-violence arising from SN usage amongst children/teenagers or against women, e-inclusion and solidarities arising from social network usage.

In this issue, the focus of the five papers is mostly on youth but Philip Effiom Ephraim alludes also to gender

\footnotetext{
${ }^{1}$ For more information see the report Rizza and Guimarães Pereira (2013).
} 
based problems. More specifically, all papers present and discuss ethical considerations related to (mostly) young persons, use of $\mathrm{SN}$ in different geographical locations: Europe, United-States, Australia and Africa, exploring its impacts for those underage and for minors and addressing the cyber-bullying phenomenon and cyber-violence against girls and women.

Regarding underage users of social networking sites, Brian O'Neill discusses whether the model of shared responsibility and vigilance by industry providers together with children' guardians (parents, etc.) and children themselves for protection of minors online and, specifically of underage usage of online services, is really working. The author observes that research shows that age restrictions on social networking sites have largely proved ineffective or are widely ignored. This situation is reportedly troublesome for many children. Indeed, O'Neill argues that a duty of care applies for those who generate online services; duty of care may be defined as legal obligation on individuals or entities to ensure that a standard of reasonable care exists in view of possible harmful activities arising from online services usage. He puts a strong emphasis on the idea that, by design, protection should be embedded in technology development and that weaknesses and failure in protecting children should be viewed as shortcomings arising from design and technology owners rather than as a responsability of the users. Parents or other guardians have a key share in responsibility, but with the pace of technology change that often they do not master, it is unlikely that they can effectively intervene. Based on ideas of practical ethics, O'Neill recommends, however, that shared responsibility and "care partnerships" are essential steps to guard children from harms arising from inappropriate usage of on-line services.

For the United States context and legal framework, Kay Mathiesen takes another perspective and argues that, while parents may have a legal right to monitor their minor children's Internet use, this practice either covert or overt, can be ethically inappropriate, because when their children engage in informational exchanges with others, their privacy ought to be respected. Mathiesen considers that "paternalistic" monitoring can be ineffective, lead to harm, and affect autonomy and trust of children in their relationships. The author grounds the parental obligation to respect their children's privacy in order to respect their current capacities for autonomy and relationships, and to foster their future capacity for autonomy and relationships. She proposes that parents minimize on-line risk to their children by engaging in "social co-use" and "interactive mediation", which implies/ involves both parents and children on an on-going interactive conversation about the technologies they use daily.

The question of cyber-bullying is discussed in the papers of Tommaso Bertolotti and Lorenzo Magnani, and Philip Effiom Ephraim.
Ephraim offers an informative paper about online usage in some parts of Africa today. In many African countries, children and youths aged between 13 and 30 constitute the main users of SN. While SN provides facilities and benefits to African young people, they have also become the place or means of cyber-bullying and cyber-crime, specifically against girls and young women. Through the presentation of several cases the author proposes a cultured centred approach based on information ethics in the use of social media in order to encourage a responsible social network use by young Africans. The author emphasizes that this ethical based approach stresses respect for human rights, such as the right to life, privacy and freedom from injury, as well as, the virtue of honesty, respect for human dignity, care, loyalty etc. This culture-centred approach needs however to be matched with awareness raising activities, counselling and education amongst youths and other users.

Bertolotti \& Magnani review the roots of the cyberbullying phenomena; they argue that social networking is deep-rooted in a most ancient social phenomenon: gossip. Anthropologists consider gossip as a means of social regulation whilst evolutionary studies propose gossip as a "natural phenomenon". Proposing a philosophical and "evolutionary" approach to cyber-bullying, the authors explain the violent societal changes brought by SN through the notion of "sub-morality" and suggest that SN empowers bullying. Due to social network "undifferentiation" between levels of friendship and the encouragement of practices of self-gossip, users cannot rely on sub-group defence mechanism as they would in "real life" when confronted with harmful attacks to their reputation and hence, dignity. This effect is reinforced by what the authors call "the rupture of moral proximity".

Last but not least, the paper by Cecile Paris, et al. presents the results of a study aiming to specify social networks' potential for supporting specific groups of citizens in the Australian context and legal framework. This study, conducted in collaboration with the Australian Department of Human Services, focuses on the development and implementation of an on-line community platform called Next Step, which aims to help people receiving welfare payment to find an employment and become financially self-sufficient. Based on Mason's (1986) four key ethical concerns-namely privacy, accuracy, property, and accessibility, as well as the issues of responsibility of researchers, the authors use the specific case of this study to formulate recommendations addressed to any government willing to use $\mathrm{SN}$ for providing or engaging with special needs citizens. The "balancing act" tries to, on the one hand, ensure the privacy of community members, and on the other hand, protect them and ensure their safety and fulfil the government's legal responsibility.

In summary, we contend that several salient ethics based proposals emerge from this collection of papers: 
- Duty of care: O'Neill, and Paris et al. (specific issues related to the duty of care by providing emotional support through a continuous monitoring of the community);

- On-line safety as a co-produced enterprise: Bertolotti \& Magnani; O'Neill; Mathiesen; Ephraim (ways to enhance on-line safety without compromising other ethical values reley on shared responsibility and recognition that all members of the community have important roles to play);

- Ethics in design and by design: O'Neill (responsibility regarding the protection of the individuals from harm lies with those who promote the online service);

- Cultural-centred awareness raising: Ephraim and to a certain extent Bertolotti \& Magnani (awareness raising and policy making based on cognisant users about their rights, virtues, fundamental values).
While looking at social networks usage and challenges posed to "special needs users", this collection of papers suggest ethics based frameworks through which phenomena like on-line safety, cyber-bullying and cyber-violence can be governed in order to protect our special needs users with respect to their privacy, autonomy, and dignity while using SN.

\section{Reference}

Rizza, C., \& Guimarães Pereira, Â. (2013). Social networks and Cyber-bullying among teenagers: EU Scientific and political report. Publications Office of the European Union, pp. 1-184. ISBN:9789279289675. doi:10.2788/41784. 